\title{
Identifying safe haven assets for equity investors through an analysis of the stability of shock transmission
}

\author{
Thomas J. Flavin a , Ciara E. Morley ${ }^{\mathrm{a}}$, Ekaterini Panopoulou ${ }^{\mathrm{b}, *}$ \\ a Department of Economics, Finance \& Accounting, NUI Maynooth, Ireland \\ b Kent Business School, University of Kent, UK
}

\section{A R T I C L E I N F O}

\section{Article history:}

Received 12 January 2014

Accepted 6 August 2014

Available online 15 August 2014

\section{JEL classification:}

G11

G01

C32

\section{Keywords:}

Safe haven assets

Financial market crises

Shock transmission

Regime switching

\begin{abstract}
A B S T R A C T
Our analysis takes the perspective of an equity fund manager who seeks a potential safe haven asset to protect her portfolio during market downturns. We employ a regime-switching framework, within which we separate common and idiosyncratic shocks, to assess the suitability of gold, 10-year and 1-year U.S. Treasury bonds. We find evidence in favour of choosing either gold or the longer-dated bond as our safe haven asset. Both deliver risk reduction benefits as equity markets plunge. In contrast, the 1 -year bond is not suitable as its vulnerability to contagious idiosyncratic shocks more than offsets its ability to hedge against common risk factors.
\end{abstract} (C) 2014 Elsevier B.V. All rights reserved.

\section{Introduction}

As financial asset prices plunged in the midst of the recent financial crisis, the subject of 'safe haven assets' once again came into sharp focus in the minds of investors and financial commentators alike.

\footnotetext{
* Corresponding author at: Kent Business School, University of Kent, Canterbury CT2 7PE, United Kingdom. Tel.: +44 1227824469 .

E-mail addresses: thomas.flavin@nuim.ie (T.J. Flavin), ciara.e.morley@nuim.ie (C.E. Morley), A.Panopoulou@kent.ac.uk (E. Panopoulou).
} 
Safe haven assets are essentially risk diversifiers that are held to improve the risk-return tradeoff of asset portfolios in times of market turbulence. Their role in the portfolio is to alleviate the effects of an adverse shock to the main asset class held by the fund manager. The most-sought-after safe asset would exhibit negative correlation during bear market episodes and positive correlation during bull markets.

There are several definitions of a safe haven asset in the existing literature. ${ }^{1} \mathrm{~A}$ broad definition is an asset with low market risk and high liquidity that is sought when investors become nervous of market losses. This is similar to the definition employed by Kaul and Sapp (2006) where a safe haven is any asset that investors are drawn to in uncertain times. A more easily quantifiable metric comes from Baur and McDermott (2010) and Baur and Lucey (2010) who define a safe haven as one that has a zero or negative correlation with the risky portfolio during market downturns. Building on these insights, we propose a more stringent definition that requires both the first- and second-order moments of the candidate safe haven asset to be insulated from negative shocks in another market.

Our empirical analysis employs a regime-switching framework and takes the perspective of an equity fund manager who seeks to identify potential safe haven assets to protect her portfolio. Chan et al. (2011) also analyse asset market linkages using a regime-switching methodology, focusing on the changing relationships of assets from three different classes between two regimes. Our aim is similar but we adopt a model to facilitate a much finer disaggregation of the risk sources by decomposing asset returns into common and idiosyncratic factors. This is particularly useful here as an equity investor who takes a long position in a safe haven asset is exposing themselves to a common shock as well as idiosyncratic shocks. As all three shocks are allowed to transit independently between two regimes, it yields eight distinct regimes and allows us to present a richer analysis of asset relationships across different asset market conditions. The stability of the transmission of both common and idiosyncratic shocks across regimes is analysed within a unified framework. To complete the analysis, we assess the relative importance of common and idiosyncratic shocks in determining asset return comovements. We investigate the joint behaviour of equity with three potential safe haven assets, namely gold, long-term U.S. Treasury bonds and a 1-year Treasury bill.

The choice of our candidate safe haven assets stems from a trawl of the extant literature, which is reviewed in the next section. Much of the early literature, e.g. Fleming et al. (1998), focused on the stock-bond relationship and the findings are generally in favour of government bonds providing the equity investor with a 'safe' alternative in times of crisis. A more recent strand of the literature has turned the attention towards gold, e.g. Baur and McDermott (2010) and Baur and Lucey (2010). Much of this has been sparked by the outstanding performance of gold immediately prior to and during the most recent financial crisis of 2007-2009. Indeed, headlines in the popular media seem to have already conferred safe haven status on gold, e.g. in 2008, the Financial Times ${ }^{2}$ stated "Gold set to cement safe haven status" while in 2011, CNBC $^{3}$ asked "Is gold the only safe haven investment left?"

Thus, against this backdrop, we re-examine this issue with an aim to identify which of these potential safe haven candidates actually offers the best protection against adverse asset price movements to an equity investor. The rest of the paper is organised as follows. Section 2 reviews the relevant literature on the stock-bond and stock-gold relationships. Section 3 outlines the econometric model used and describes the data. Section 4 reports our empirical findings, while our concluding remarks are contained in Section 5.

\section{Literature review}

\subsection{The stock-bond relationship}

Much of the early literature on safe haven assets concentrates on the stock-bond relationship. Fleming et al., 1998 and Scruggs and Glabadanidis (2003) find that the bond market variance is

\footnotetext{
1 McCauley and McGuire (2009) compile a number of these definitions.

2 Available at: http://www.ft.com/intl/cms/s/0/9d002228-8eb9-11dd-946c-0000779fd18c.html

3 Available at: http://www.cnbc.com/id/44193266
} 
relatively unresponsive to stock return shocks, thereby identifying one appealing characteristic of bonds as a potential safe haven asset. Furthermore De Goeij and Marquering (2004) conclude that there is strong evidence of conditional heteroskedasticity in the covariance matrix of stock and bond market returns and not only variances but also covariances respond asymmetrically to return shocks. Cappiello et al. (2006) find evidence of asymmetries in conditional correlations in response to negative returns, with equity exhibiting stronger responses than bonds to joint bad news.

A number of studies also document declining correlations between stock and bond markets. For the UK, Steeley (2006) finds a reversal in the sign of this correlation, from positive to strongly significantly negative over his twenty year sample. Kim et al., 2006 also find obvious downward trends in time-varying correlations between stock and bond market returns in Europe, Japan and the US. More recently, however Baele et al., 2010 find that this 'trend' has not persisted and that the stock-bond return correlation displays much time variation.

Many studies argue that time-varying correlations are more likely to be in response to market conditions and may represent a 'flight-to-quality' phenomenon. For example, De Goeij and Marquering (2004) find that the covariance between stocks and bonds tends to be relatively low after bad news in the stock market and good news in the bond market. Connolly et al., 2005 note in their regime-switching analysis that there are two sharply defined regimes. The first of these is a relatively normal, low uncertainty regime where the stock-bond return relation is substantially positive and the second is a relatively abnormal, high uncertainty regime in which the stock-bond return relation is modestly negative. Guidolin and Timmermann (2006) also document significant variation in correlation across regimes with negative correlation between stocks - both large- and small-capitalisation stocks - and bonds in the 'crash' regime of their model. Andersson et al., 2008 examine the impact of perceived stock market uncertainty on the time-varying correlation between U.S. Treasury bonds and stock markets and German bond and stock markets between 1994 and 2004. They conclude that sustained periods of negative correlation are observed and that the time-varying correlation has a tendency to change substantially and turn negative in a very short period of time. Since negative correlation is desired during stock market downturns, these findings greatly increase the appeal of government bonds as a potential safe haven. Chan et al. (2011) find that U.S. Treasury bonds act as a safe haven for equity investors during market turbulence.

\subsection{The stock-gold relationship}

The academic literature on the relationship between equity and gold is more recent and relatively sparse. Coudert and Raymond (2011) outline the properties of gold that lead it to being a potential safe haven even though volatility is characteristically high. They note gold's historical role as a medium of exchange in international monetary exchange, hinting that it may still be the ultimate safe haven. Lawrence (2003) also provides insight into the evolving relationship between gold and the stock market. He concludes that gold appears to be insulated from the business cycle - in contrast to other commodities - which may make it more attractive as a diversifier and indeed as a safe haven. Baur and McDermott (2010) find that gold acts as a safe haven for most developed market investors but has a relatively minor role in emerging markets. However, they believe that gold plays a role in stabilising the financial system in the wake of extreme negative shocks. Similarly, Baur and Lucey (2010) find that gold acts as a safe haven during periods of large negative stock market returns but show empirically that the safe haven characteristics are short-lived.

Without explicitly considering its role as a safe haven, a number of papers analyse the effects of adding gold to a portfolio of financial assets. Jaffe (1989) shows that the inclusion of gold in a portfolio shifts the portfolio frontier to the left, allowing investors to reduce risk and also increase return. This combination makes gold a very attractive investment opportunity. Likewise, Hillier et al., 2006 find that any financial portfolio containing a moderate weighting of gold tends to outperform those comprised only of financial assets. 


\section{Econometric methodology and data}

\subsection{Econometric model}

We adopt the methodology of Flavin et al., 2008 which is an extension of the model developed by Gravelle et al. (2006), to test for contagion between pairs of markets. The latter were solely interested in the stability of the common shock, while the former adds the required structure to allow for a simultaneous test of bi-directional pure contagion, i.e. when a shock that is asset specific during normal times, spills over to other assets during market downturns. This framework is well suited to assessing the stability between pairs of markets, making it an ideal model for gauging the credentials of our potential safe haven assets. Here, we sketch the main features of the model.

The model is bivariate and belongs to the family of factor models widely used in financial economics. Let $r_{i t}$ represent the excess log return of each series $i$. Returns are decomposed into an expected, $\mu_{i}$, and an unexpected component, $u_{i t}$, and can be written as,

$$
r_{i t}=\mu_{i}+u_{i t}, \quad E\left(u_{i t}\right)=0, \quad i=E, S H \text { and } E\left(u_{1 t}, u_{2 t}\right) \neq 0
$$

where $E$ and $S H$ refer to equity and the potential safe haven, respectively. The error terms are allowed to be contemporaneously correlated, thus capturing common shocks. Hence, the errors can be decomposed into a common shock and an idiosyncratic shock,

$$
u_{i t}=\sigma_{c i t} z_{c t}+\sigma_{i t} z_{i t}, \quad i=E, S H
$$

where $z_{c t}$ and $z_{i t}$ denote the common and idiosyncratic shocks, respectively and $\sigma_{c i t}$ and $\sigma_{i t}$ measure the impact of the structural shocks on the series returns. Shock variances are normalised to unity, so the impact coefficients may be interpreted as standard deviations.

The common and idiosyncratic shocks are allowed to, independently from each other, switch between a low- and a high-volatility state. The structural impact coefficients switch regimes as follows:

$$
\begin{aligned}
& \sigma_{i t}=\sigma_{i}\left(1-S_{i t}\right)+\sigma_{i}^{*} S_{i t}, \quad i=E, S H \\
& \sigma_{c i t}=\sigma_{c i}\left(1-S_{c t}\right)+\sigma_{c i}^{*} S_{c t}, \quad i=E, S H
\end{aligned}
$$

where state variables $S_{i t}=(0,1)$, take a value of zero in normal times and a value of unity in turbulent times and parameters with an asterisk belong to the high-volatility regime. Since the state variable $S_{i t}$ is unobservable, probabilistic inferences of its value must be formed. Regime paths are allowed to change endogenously and are Markov-switching. This framework facilitates sudden jumps between low- and high-volatility regimes with the following transition matrix,

$$
p=\left[\begin{array}{ll}
p\left(S_{t}=0 \mid S_{t-1}=0\right) & p\left(S_{t}=1 \mid S_{t-1}=0\right) \\
p\left(S_{t}=0 \mid S_{t-1}=1\right) & p\left(S_{t}=1 \mid S_{t-1}=1\right)
\end{array}\right]
$$

Furthermore, we relax the assumption of expected constant returns in (1). These are allowed to be time varying and depend on the state of the common shock. ${ }^{4}$ In particular, expected returns are modelled as follows:

$$
\mu_{i t}=\mu_{i}\left(1-S_{c t}\right)+\mu_{i}^{*} S_{c t}, \quad i=E, S H .
$$

As in Flavin et al. (2008), we allow the idiosyncratic shock of one market to potentially exert an influence on the other market during turbulent periods, over and above that captured by the common shock. It is modelled by augmenting the return equation of market $i$ with the idiosyncratic shock of market $j(i \neq j)$ during the crisis period. Any spillover from such a shock represents instability in the system which will have a bearing on the safe haven characteristics of our assets. The instability arises due to new channels of transmission becoming active during high-volatility regimes. This can be seen

\footnotetext{
${ }^{4}$ Given that idiosyncratic and common shocks are uncorrelated and the former are mainly associated with diversifiable risk, expected returns are only allowed to vary with the volatility state of the common shock.
} 
by contrasting the variance-covariance matrices associated with the extreme regimes, given in Eqs. (6) and (7) below.

The model is estimated as a complete system and has eight distinct regimes. To illustrate the potential channels of instability, we present a simplified example. For example, if we take the extreme states, the characteristics of the model during tranquil periods (all shocks in the low-volatility states) are given as follows:

$$
\begin{aligned}
& r_{E, t}=\mu_{E}+\sigma_{c E} z_{c, t}+\sigma_{E} z_{E, t} \\
& r_{S H, t}=\mu_{S H}+\sigma_{c S H} z_{c, t}+\sigma_{S H} z_{S H, t}
\end{aligned}
$$

The idiosyncratic shocks are assumed to be independent, so co-movements are solely determined by the common shock. Thus, the covariance matrix of returns is given by:

$$
\Sigma_{1}=\left[\begin{array}{cc}
\sigma_{E}^{2}+\sigma_{c E}^{2} & \sigma_{c E} \sigma_{c S H} \\
\sigma_{c E} \sigma_{C S H} & \sigma_{S H}^{2}+\sigma_{c S H}^{2}
\end{array}\right]
$$

At the other extreme, when all shocks in their high-volatility states, the corresponding return generating process during periods of turbulence is given by

$$
\begin{aligned}
& r_{E, t}=\mu_{E}^{*}+\sigma_{c E}^{*} z_{c, t}+\sigma_{E}^{*} z_{E, t}+\delta_{E} \sigma_{S H}^{*} z_{S H, t} \\
& r_{S H, t}=\mu_{S H}^{*}+\sigma_{c S H}^{*} z_{c, t}+\sigma_{S H}^{*} z_{S H, t}+\delta_{S H} \sigma_{E}^{*} z_{E, t}
\end{aligned}
$$

The variance covariance matrix of returns is:

$$
\Sigma_{8}=\left[\begin{array}{cc}
\sigma_{E}^{* 2}+\sigma_{c E}^{* 2}+\delta_{E}^{2} \sigma_{S H}^{* 2} & \sigma_{c E}^{*} \sigma_{c S}^{*}+\delta_{S H} \sigma_{E}^{* 2}+\delta_{E} \sigma_{S H}^{* 2} \\
\sigma_{c E}^{*} \sigma_{C S H}^{*}+\delta_{S H} \sigma_{E}^{* 2}+\delta_{E} \sigma_{S H}^{* 2} & \sigma_{S H}^{* 2}+\sigma_{c S H}^{* 2}+\delta_{S H}^{2} \sigma_{E}^{* 2}
\end{array}\right]
$$

Comparing Eqs. (6) and (7), the additional term in the return generating process of market $i\left(\delta_{i} \sigma_{j}{ }_{j} z_{j}\right)$ detects and measures the importance of spillovers during episodes of high-volatility in the idiosyncratic shock of market $j$.

\subsubsection{Testing for stability in the transmission of the common shock}

We posit that the transmission mechanism is stable if a large unexpected shock affecting both assets does not change their interdependence. Thus, increases in the variance and correlation of returns during crisis periods are due to increased impulses stemming from the shared risk factors and not from a change to the transmission mechanism governing the process. Our test for stability is constructed by specifying the null and alternative hypotheses as follows:

$$
H_{0}: \frac{\sigma_{c S H}^{*}}{\sigma_{c E}^{*}}=\frac{\sigma_{c S H}}{\sigma_{c E}} \text { versus } H_{1}: \frac{\sigma_{C S H}^{*}}{\sigma_{c E}^{*}} \neq \frac{\sigma_{c S H}}{\sigma_{c E}}
$$

Under the null hypothesis, the impact coefficients in both calm and crisis periods move proportionately. We compute a statistic $\gamma$

$$
\gamma=\frac{\sigma_{c S H}^{*} \sigma_{c E}}{\sigma_{c E}^{*} \sigma_{c S H}}
$$

which is unity when the transmission of the common shock is stable. A value of $\gamma$ greater than unity suggests a proportionately stronger reaction from equity, while $\gamma<1$ implies a stronger reaction from the safe haven asset, to the common news. To test if $\gamma=1$, a likelihood ratio test is employed and follows a $\chi^{2}$ distribution with one degree of freedom corresponding to the restriction of equality of the ratio of coefficients between the two regimes. The role of a safe haven asset is to dampen the effects of an adverse common shock so therefore investors would like $\gamma \geq 1$. 
Table 1

Summary statistics.

\begin{tabular}{lllll}
\hline & $\begin{array}{l}\text { Excess return } \\
\text { S\&P500 }\end{array}$ & $\begin{array}{l}\text { Excess return } \\
\text { Gold }\end{array}$ & $\begin{array}{l}\text { Excess return } \\
10 \text {-Year bond }\end{array}$ & $\begin{array}{l}\text { Excess return } \\
1 \text {-Year bond }\end{array}$ \\
\hline Mean & 0.0005 & -0.0003 & 0.0006 & 0.00005 \\
St. Deviation & 0.0230 & 0.0254 & 0.0116 & 0.0020 \\
Skewness & -0.6966 & 0.2956 & 0.2466 & 1.1101 \\
Excess Kurtosis & 4.8946 & 6.1430 & 2.6686 & 16.1872 \\
Jarque-Bera & 1857.15 & 2731.11 & 528.13 & $19,143.05$ \\
Observations & 1721 & 1721 & 1721 & 1721 \\
\hline
\end{tabular}

Notes: Returns are in excess of the 3-month U.S. Treasury bill rate. Skewness is defined as $m_{3} / s^{3}$ where $m_{3}$ is the centred third moment of the data and $s$ is the sample standard deviation. Kurtosis is defined as $\left(m_{4} / s^{4}\right)-3$ where $m_{4}$ is the centred fourth moment of the data.

\subsubsection{Testing for stability in the transmission of idiosyncratic shocks}

By definition, idiosyncratic shocks are asset-specific. However, if the system becomes unstable as we transit from a low- to a high-volatility state, the idiosyncratic shock of market $i$ can potentially exert an influence in market $j$, a phenomenon referred to as pure contagion in the literature. Our test for instability of these types of shock from market $i$ to market $j$ is a simple $t$-test on the coefficient $\delta_{j}$, where under the null $\delta_{j}=0$ and there is no spillover or instability. A non-zero value of $\delta_{j}$ contains additional information about the relationship between the asset pairs. A positive value of the parameter implies that a negative, high-volatility, shock to asset $i$ depresses the return on asset $j$, while their correlation also increases. This is an example of contagion and is bad news for investors. In contrast, a negative value implies that adverse news for asset $i$ actually increases the return on asset $j$, while decreasing their correlation. This represents a flight-to-quality, as the asset returns move in opposite directions and thus help to reduce portfolio losses.

\subsection{Data}

Our sample spans thirty-two years of weekly data from 9th January 1980 to 26th December 2012, yielding a total of 1721 observations. ${ }^{5}$ We prefer to work with weekly excess returns since they tend to be less serially correlated and alleviate the problems associated with non-synchronous data. We take the perspective of a U.S. equity investor so all assets are domestic and denominated in U.S. dollars. The Standard \& Poor's Composite 500 index represents the U.S. stock market. Gold prices are taken as the closing US\$/per troy ounce price on the London Bullion Market (LBM). A Datastream-constructed total return index for a benchmark 10-year U.S. Treasury bond provides a proxy for the long-term government bond market, while the 1-year U.S. Constant Maturity Treasury (CMT) represents the shorter end of the U.S. Treasury bond yield curve. ${ }^{6}$ To ensure series are stationary, excess log returns are calculated using the 3-month U.S. Treasury Bill as a proxy for the risk free rate of return. All data are sourced from Datastream.

Table 1 provides summary statistics for each of our asset return series. Interestingly, gold is the only asset that records a negative average excess return over the sample. All other assets have positive excess returns with equity and the long-term bond having similar mean returns. Both equity and gold are much riskier than U.S. Treasuries with the short-term bond offering the most stable return. Gold, if held in isolation gives the worst risk-return trade-off, as it is the most risky and has the lowest return. The skewness measure is also interesting, with only equity having a negative statistic. All others exhibit positive skewness so that, on average, there may be some potential for creating more stable, diversified portfolios. All assets have leptokurtosis and normality is decisively rejected in all

\footnotetext{
${ }^{5}$ Cappiello et al. (2006) and Gravelle et al. (2006) also employ weekly returns. Baur and McDermott (2010) report that their results are qualitatively similar using daily, weekly or monthly returns.

${ }^{6}$ We follow the Morningstar methodology paper (2008) in computing weekly holding period returns from the 1-year CMT series.
} 
Table 2

Estimate of mean returns across regimes.

\begin{tabular}{|c|c|c|c|c|c|c|}
\hline & $\mu_{E}$ & $\mu_{S H}$ & $\mu_{E}^{*}$ & $\mu_{S H}^{*}$ & LR & $p$-Value \\
\hline Gold & $\begin{array}{l}0.13 \\
(1.22)\end{array}$ & $\begin{array}{l}-0.20 \\
(-3.46)\end{array}$ & $\begin{array}{l}0.15 \\
(2.44)\end{array}$ & $\begin{array}{l}0.09 \\
(1.13)\end{array}$ & $8.72^{* * *}$ & 0.01 \\
\hline 10-Year bond & $\begin{array}{l}\text { 0.19 } \\
(3.30)\end{array}$ & $\begin{array}{l}0.09 \\
(2.31)\end{array}$ & $\begin{array}{l}0.09 \\
(1.15)\end{array}$ & $\begin{array}{l}-0.01 \\
(-0.61)\end{array}$ & $5.01^{*}$ & 0.08 \\
\hline 1 -Year bond & $\begin{array}{l}\text { 0.19 } \\
(3.87)\end{array}$ & $\begin{array}{c}-0.007 \\
(-3.21)\end{array}$ & $\begin{array}{l}-0.27 \\
(-1.85)\end{array}$ & $\begin{array}{l}0.01 \\
(3.68)\end{array}$ & $30.88^{* * *}$ & 0.00 \\
\hline
\end{tabular}

Notes: $\mu_{E}$ and $\mu_{S H}$ report the expected mean returns in the low-volatility regime for equity and the safe haven asset respectively, while the starred parameters refer to the corresponding estimates for the high-volatility regime. $t$-statistics are reported in parentheses under coefficients. Bold numbers indicate statistical significant values. The likelihood ratio statistic is for the null of equality of mean returns across the regimes. The test statistic has a Chi-square (2) distribution under the null hypothesis.

* Significance at the $10 \%$ level.

*** Significance at the $1 \%$ level.

cases. This is consistent with the fact that we may need more than one regime present to capture the asset return distributions.

\section{Results}

\subsection{Mean returns}

We begin our analysis by testing for equality of mean returns across the two regimes of the common shock. Table 2 reports our results. Columns 1 and 2 report the expected mean returns in the lowvolatility regime for equity and the safe haven asset respectively, while the corresponding estimates for the high-volatility regime are reported in columns 3 and 4. In all cases, we reject the restriction of equal means so in the remainder of the paper, we progress with models that allow for the expected return to vary by the regime of the common shock. Table 2 reveals some further insights. In the stock-bond pairings, we observe the usual pattern whereby the turbulent regime is associated with declining equity returns (although it's only negative for the pairing with the 1-year bond). The reason for this is that equity volatility is dominating the regime switch and it is a stylised fact that negative equity market shocks are associated with high volatility and falling returns (e.g. see Schwert, 1989). The bond return falls in the case of the longer-horizon bond, while showing a modest increase for the shorter-dated bond. The equity-gold pairing shows a different pattern. Here both assets are highly volatile and hence the high volatility common shocks are not exclusively associated with negative equity shocks but also due to conditions in the market for gold. We find that the common shock is much more frequently in the high-volatility regime relative to the pairs containing a Treasury bond (the frequency of all shocks is discussed and analysed in Section 4.4 and Fig. 1). For the equity-gold pair, the high-volatility regime of the common shock is characterised by a strong increase in the gold return and a more modest increase in the equity return. Safe haven assets with an increasing return in the high-volatility regime are likely to offer better portfolio protection to an equity investor and this will be analysed later.

\subsection{Transmission of the common shock}

In assessing the stability of the asset return relationships, we initially focus on the common shock. Fig. 1 displays the filtered probability of the common shock being in the high-volatility regime for each pair of assets. There are pronounced and persistent periods of high-volatility in the common shock for equity and each of the three potential safe havens. Interestingly, the high-volatility regimes match crises and recessions over the past thirty years, for example, the 1987 stock market crash and more notably the most recent 2008 financial crisis. The pairings of equity with the 10- and 1-year U.S. Treasury bonds exhibit high probability of being in the high-volatility state during the most recent NBER dated recession, of mid-2008 to mid-2009. The equity-gold pairing is more persistently in this 
(a) Gold

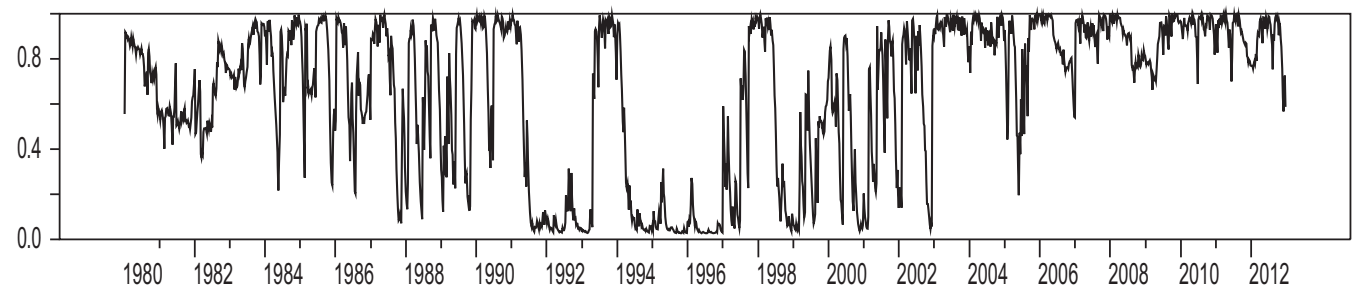

(b) 10 Year Bond

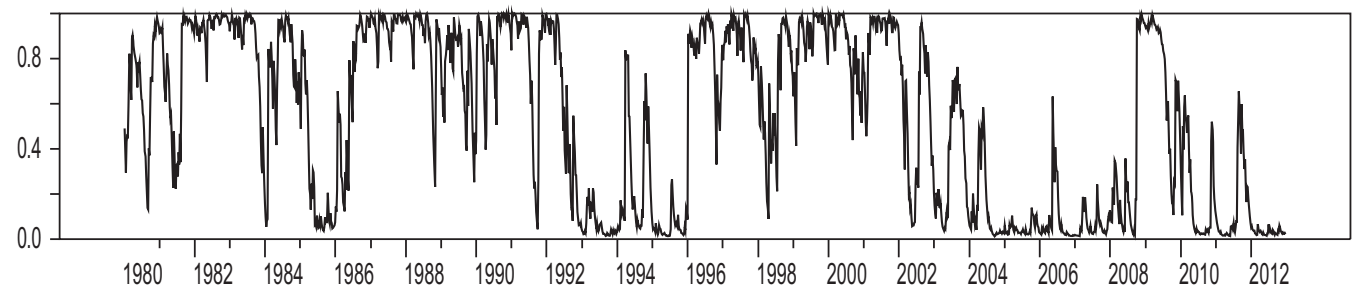

(c) 1 Year Bond

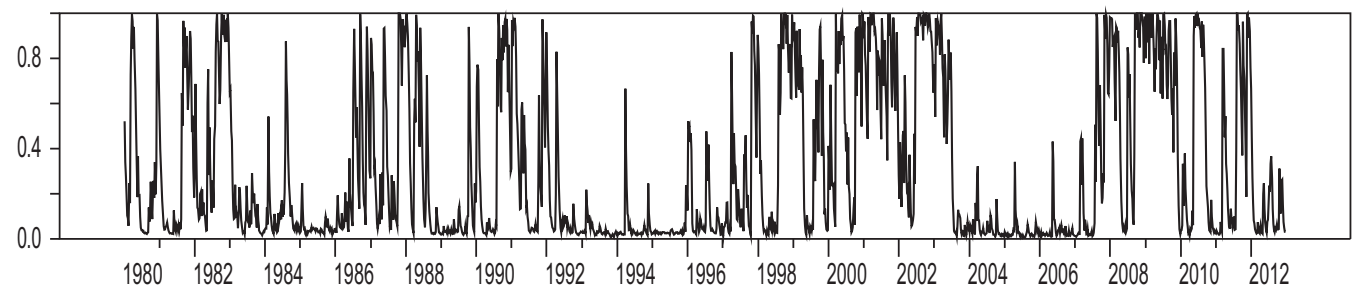

Fig. 1. Filter probabilities of high-volatility common shocks between equity and: (a) gold, (b) 10-year bond, (c) 1-year bond.

turbulent state post-2007. Episodes of high-volatility common shocks are not limited to recession periods however and for gold and the 10-year bond, there are many sustained periods of common turbulence.

Table 3 reports the relevant information pertaining to the transmission of the common shock. Columns 2 and 3 report the impact coefficients for equity and the safe haven asset during the 'normal' regime respectively, while columns 4 and 5 contain the equivalent information for the turbulent regime. In general, asset returns display heightened sensitivity to the common shock during these 'crisis' periods. Column 6 reports our $\gamma$ statistic that should be unity if the propagation mechanism of the common shock is stable. Recall also that a value less (greater) than unity implies a stronger (smaller) response from the safe haven asset relative to equity during the period of high-volatility common shocks. For the equity-gold pair, our ratio is less than unity, which may be of concern for an equity investor as the potential safe haven asset appears more sensitive to common risk than equity. However, the likelihood ratio test (column 7) is unable to reject the hypothesis that $\gamma=1$ and that the transmission of the common shock is stable between regimes. For both pairs that contain equity and a Treasury bond, the ratio is greater than unity, consistent with the potential safe haven asset being less affected by a common shock than equity. As with gold, there is no statistical evidence that the relationship between equity and the 10-year bond changes during episodes of high common risk. However, for the 1-year bond we can reject the hypothesis that the transmission is stable. On closer inspection, this rejection stems from the fact the 1-year bond displays no change in sensitivity as we change regime. In fact, the shorter-dated bond is unaffected by the common shock in both regimes but 
Table 3

Estimate of impact coefficients of common shocks.

\begin{tabular}{|c|c|c|c|c|c|c|c|}
\hline & $\sigma_{c E}$ & $\sigma_{c S H}$ & $\sigma_{c E}^{*}$ & $\sigma_{c S H}^{*}$ & $\gamma$ & LR & $p$-Value \\
\hline Gold & $\begin{array}{l}5.5 e-04 \\
(0.10)\end{array}$ & $\begin{array}{l}2.5 e-04 \\
(0.17)\end{array}$ & $\begin{array}{l}0.161 \\
(1.86)\end{array}$ & $\begin{array}{l}1.842 \\
(19.37)\end{array}$ & 0.039 & $6.8 \mathrm{e}-05$ & 0.99 \\
\hline 10-Year bond & $\begin{array}{l}0.009 \\
(0.05)\end{array}$ & $\begin{array}{l}1.3 e-04 \\
(0.03)\end{array}$ & $\begin{array}{l}1.744 \\
(16.24)\end{array}$ & $\begin{array}{l}0.468 \\
(7.56)\end{array}$ & 3.908 & $2.4 \mathrm{e}-05$ & 0.99 \\
\hline 1 -Year bond & $\begin{array}{l}1.510 \\
(27.74)\end{array}$ & $\begin{array}{l}2.3 e-09 \\
(0.03)\end{array}$ & $\begin{array}{l}3.445 \\
(23.83)\end{array}$ & $\begin{array}{l}2.4 \mathrm{e}-09 \\
(0.03)\end{array}$ & 2.382 & $20.88^{* * *}$ & 0.00 \\
\hline
\end{tabular}

Notes: $\sigma_{c E}$ and $\sigma_{c S H}$ refer to the impact coefficients of common shocks for equity and the safe haven asset during the lowvolatility regime respectively, while the starred parameters contain the equivalent information for the high-volatility regime. $t$-statistics in parentheses under coefficients. Bold numbers indicate statistical significant values. $\gamma$ is the ratio of responses to a common shock in the high- to the low-volatility regime and is discussed above. The likelihood ratio (LR) statistic is for the null of no shift contagion $\left(\mathrm{H}_{0}: \gamma=1\right)$ against the alternative of shift contagion between S\&P500 and the indicated assets. The test statistic has a Chi-square distribution under the null hypothesis.

*** Significance at the $1 \%$ level.

there is a substantial increase in sensitivity to the common shock for equity as we transit to the highvolatility regime. This differential between the two assets leads to a conclusion that the transmission mechanism is unstable for the common shock. It can be argued this rejection is a positive finding for the equity investor. The 1-year bond acts a zero-beta asset in both regimes and consequently offers a safe haven to the equity investor from common risk sources.

However, before we can choose the best safe haven options, we need to analyse the idiosyncratic shocks and the relative importance of all risk sources.

\subsection{Tests for pure contagion}

We now analyse the idiosyncratic shocks of each asset pair to ascertain if they behave differently in low- and high-volatility regimes. First, we present the filtered probabilities of each idiosyncratic shock being in the turbulent state. In particular, Fig. 2 shows the equity-specific shock for each pair, while Fig. 3 deals with the candidate safe haven assets.

Focusing on the equity shock, we see a marked difference in its behaviour across assets. Its idiosyncratic shock is most often in the high-volatility regime when paired with gold and least with the 1-year bond. Once again, the turbulent periods can be linked to known crisis periods, such as the 1987 crash, the dot.com collapse and the recent financial crisis.

Fig. 3 depicts a different story. The idiosyncratic shocks of the candidate safe haven assets exhibit much less probability of being in the turbulent state in the case of gold and the 10-year Treasury but the 1-year bond is frequently in this state. Once the commonality is removed, the true asset-specific risks are relatively rare for gold and the longer-dated bond. This is especially true for gold with most of the turbulence in the early part of the sample when its price fluctuated widely.

Table 4 presents our statistical results. The first striking feature is that the impact coefficients are much larger for the idiosyncratic shocks relative to their common counterpart. It appears that when faced with similarly sized common and idiosyncratic shocks, asset returns are much more affected by the latter. This supports the portfolio benefits of including safe haven assets since the idiosyncratic shocks that investors wish to hedge exert a greater influence on asset returns than the common shock that the diversified portfolio is exposed to.

Spillovers during crisis periods are captured by the $\delta_{i}$ coefficients. All are statistically different from zero, suggesting that high-volatility idiosyncratic shocks are rarely self-contained during episodes of heightened market sensitivity but more often act as an additional common risk factor. In particular, the $\delta_{E}$ parameter captures spillovers from the candidate safe haven to the equity market. All are positive, implying a pure contagion effect. This is potentially worrying for the equity fund manager who wishes to identify a safe haven asset and the extent of this contagion will depend on the frequency and persistence of these idiosyncratic shocks. We examine the relative importance of shocks in the next subsection. 


\section{(a) Gold}

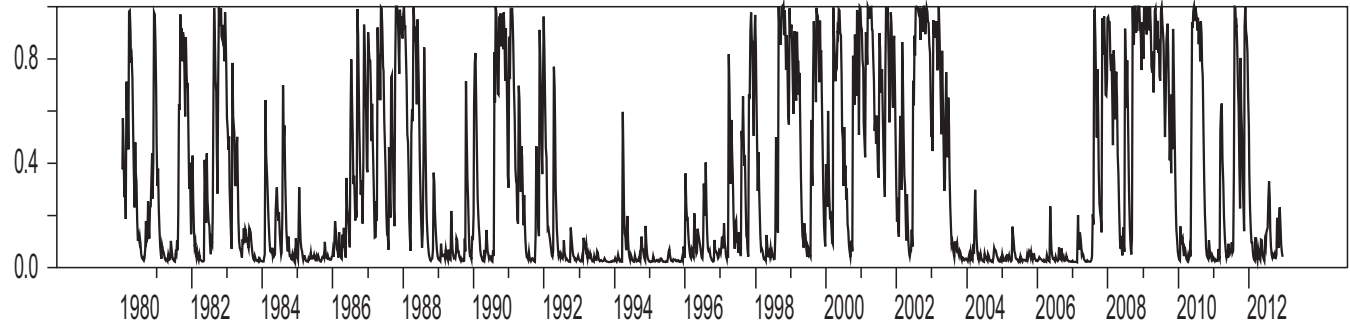

(b) 10 Year Bond

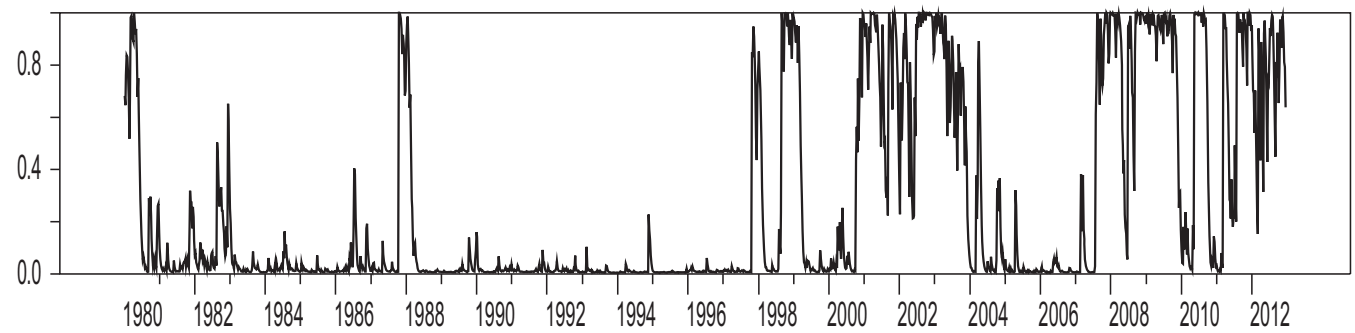

(c) 1 Year Bond

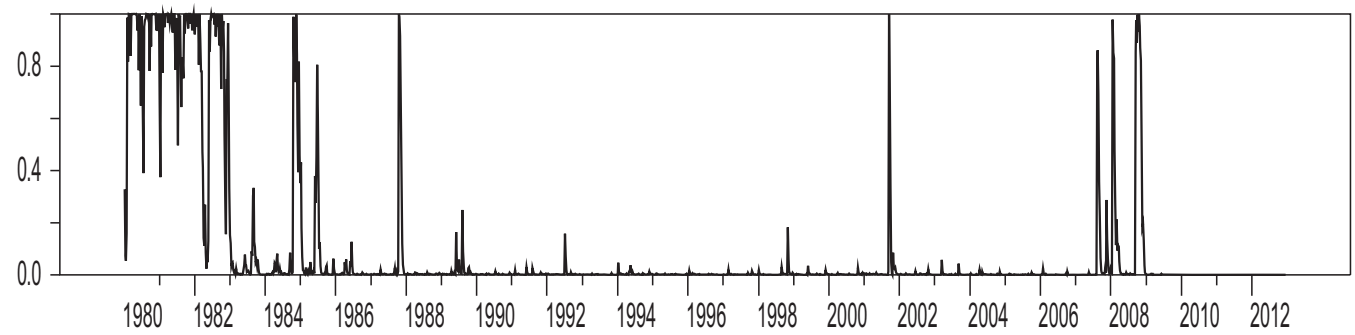

Fig. 2. Filter probabilities of equity idiosyncratic shock being in the high-volatility regime in pairing with (a) gold, (b) 10-year bond, (c) 1-year bond.

Table 4

Estimate of impact coefficients for the idiosyncratic shocks.

\begin{tabular}{|c|c|c|c|c|c|c|}
\hline & $\sigma_{E}$ & $\sigma_{S H}$ & $\sigma_{E}^{*}$ & $\sigma_{S H}^{*}$ & $\sigma_{E}$ & $\sigma_{S H}$ \\
\hline Gold & $\begin{array}{l}1.54 \\
(30.39)\end{array}$ & $\begin{array}{l}1.10 \\
(17.74)\end{array}$ & $\begin{array}{l}3.32 \\
(23.08)\end{array}$ & $\begin{array}{l}4.31 \\
(18.45)\end{array}$ & $\begin{array}{l}0.17 \\
(4.51)\end{array}$ & $\begin{array}{l}-0.10 \\
(-3.91)\end{array}$ \\
\hline 10-Year bond & $\begin{array}{l}1.24 \\
(26.03)\end{array}$ & $\begin{array}{l}0.08 \\
(32.29)\end{array}$ & $\begin{array}{l}2.93 \\
(19.21)\end{array}$ & $\begin{array}{l}1.71 \\
(12.14)\end{array}$ & $\begin{array}{l}0.40 \\
(4.86)\end{array}$ & $\begin{array}{l}-0.27 \\
(-13.62)\end{array}$ \\
\hline 1-Year bond & $\begin{array}{l}0.0001 \\
(0.12)\end{array}$ & $\begin{array}{l}0.04 \\
(24.18)\end{array}$ & $\begin{array}{l}0.44 \\
(2.50)\end{array}$ & $\begin{array}{l}0.13 \\
(33.12)\end{array}$ & $\begin{array}{l}2.66 \\
(5.58)\end{array}$ & $\begin{array}{l}1.20 \\
(2.55)\end{array}$ \\
\hline
\end{tabular}

Notes: $\sigma_{E}$ and $\sigma_{S H}$ refer to the impact coefficients of idiosyncratic shocks for equity and the safe haven asset during the lowvolatility regime respectively, while the starred parameters contain the equivalent information for the high-volatility regime. $\delta_{E}$ and $\delta_{S H}$ capture spillovers during a high-volatility regime to the equity and safe haven asset respectively. $t$-statistics in parentheses under coefficients. Bold numbers indicate statistical significant values. 


\section{(a) Gold}

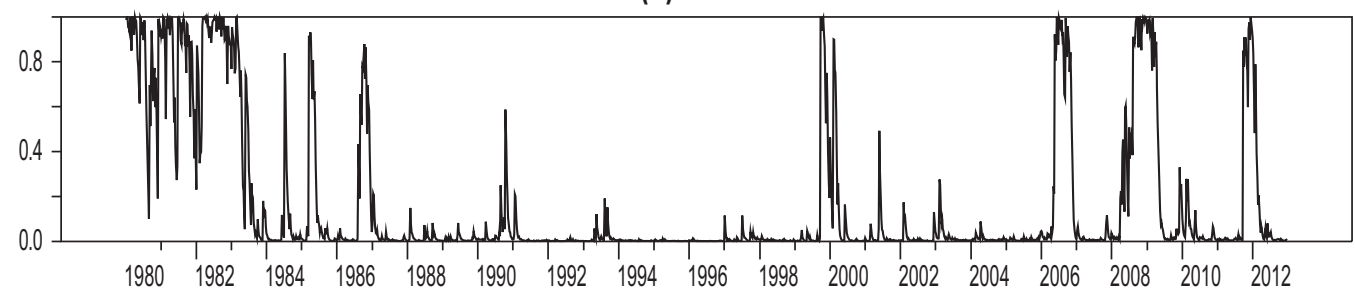

(b) 10 Year Bond

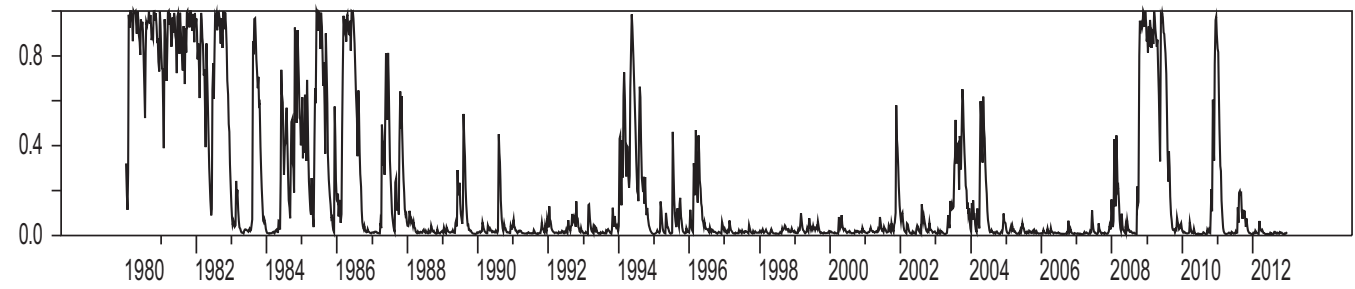

(c) 1 Year Bond

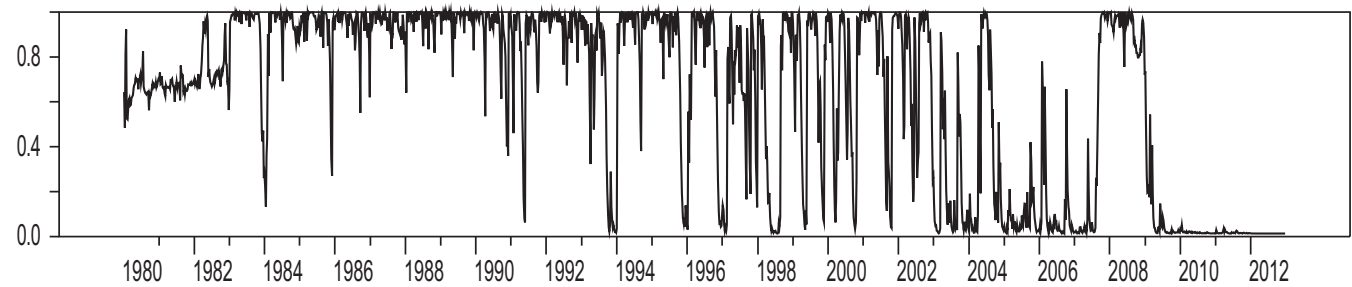

Fig. 3. Filter probabilities of safe haven idiosyncratic shock being in high-volatility regime.

The effect of the equity market idiosyncratic shock on the safe haven asset is captured by the $\delta_{S H}$ parameter. We see important differences across the assets. For the long-maturity Treasury bond and gold, this parameter is negative. This implies that these assets deliver some desirable characteristics associated with safe haven assets, namely an increase in mean returns coupled with a reduction in asset return correlation. This is consistent with a flight-to-quality phenomenon, whereby equity investors turn to these 'safer' assets in times of high-volatility equity shocks to offset the adverse environment in the stock market. In contrast, the 1 -year Treasury bond has a positive $\delta_{S H}$ parameter. This is consistent with pure contagion, whereby adverse equity shocks spillover to the 1-year bond, depressing its return and increasing their pairwise correlation. Interestingly, this is the only pair of assets for which we observe bi-directional contagion. This is a concern for investors seeking a safe haven.

\subsection{Relative importance of shocks}

When it comes to choosing the 'best' safe haven asset, our results can be sometimes conflicting. This is particularly true for the 1-year Treasury bond, which is a good hedge against common risk but not against idiosyncratic risks. Ultimately, our selection will depend on the relative importance of common and idiosyncratic shocks. We address this issue in two ways. Firstly we compute two additional statistics which we label 'Frequency' and 'Duration'. The former measures the proportion 
Table 5

Frequencies and durations of all shocks.

\begin{tabular}{|c|c|c|c|c|c|c|}
\hline & \multicolumn{2}{|l|}{ Common shock } & \multicolumn{2}{|c|}{ Equity idiosyncratic shock } & \multicolumn{2}{|c|}{ SH idiosyncratic shock } \\
\hline & Frequency (\%) & $\begin{array}{l}\text { Duration } \\
\text { (years) }\end{array}$ & Frequency (\%) & $\begin{array}{l}\text { Duration } \\
\text { (years) }\end{array}$ & Frequency (\%) & $\begin{array}{l}\text { Duration } \\
\text { (years) }\end{array}$ \\
\hline Gold & 65.24 & 1.43 & 31.30 & 0.36 & 15.13 & 0.77 \\
\hline 10-Year bond & 51.80 & 1.97 & 25.67 & 0.90 & 19.63 & 0.60 \\
\hline 1-Year bond & 30.88 & 0.32 & 9.09 & 0.49 & 63.13 & 1.21 \\
\hline
\end{tabular}

Notes: 'Frequency' measures the proportion of time that the shock is in the high volatility regime and is expressed as a percentage. 'Duration' refers to the duration of the high volatility regime of the idiosyncratic shock expressed in years.

of time for which the shock is in the turbulent regime, while the latter measures the average time for which these high-volatility shocks persist. Table 5 summarises our findings.

For the common shock, the equity - gold and equity - 10-year bond pairs spend more than half the time in the high-volatility state. Both shocks are also persistent, with durations of nearly 1.5 and 2 years respectively. In contrast the equity - 1 -year bond pair experiences high-volatility common shocks about $30 \%$ of the time and have the shortest duration at about 4 months. Recalling that the 1 -year bond provided the best protection against common risk factors and that there is no statistical evidence of instability in the other pairs, these statistics favour the equity - 1-year bond combination.

High-volatility idiosyncratic shocks induce a stronger response from all assets. We also know that such shocks to safe haven assets can produce contagious effects in the equity market. The threat of contagion makes it desirable for these shocks to have low frequency and short durations. Idiosyncratic shocks to gold have low frequency (15\%) and last for approximately 9 months. The longer-dated bond behaves similarly, experiencing turbulent shocks about $20 \%$ of the time that die out after nearly 7.5 months. However, the 1-year Treasury has a very different profile. It encounters high-volatility idiosyncratic shocks quite often and they endure for about 15 months. These findings provide support for gold and the longer-dated bond since they afford limited opportunity for contagion to occur. In contrast, the 1-year Treasury is often exposed to potentially contagious shocks that have relatively long-lasting effects.

Finally, we look at the equity-specific shock and its characteristics in a crisis regime. Recall that the equity - 1-year bond pair suffered from bi-directional contagion. It is reassuring then to find that there is very little incidence of high-volatility equity shocks for this pair. Frequency is measured at less than $10 \%$ and duration at about 6 months. For the other assets, high-volatility equity shocks trigger a 'flight-to-quality' so it is encouraging that they are more frequent than the own idiosyncratic shock for both gold and the 10-year Treasury bond. They occur less than one-third of the time. Shock durations are less than one year, substantially so for the pairing with gold, which has persistence of only about 4 months.

Given the relative strengths of common and idiosyncratic shocks in influencing asset returns, these statistics point towards either gold or the 10-year Treasury as suitable safe haven assets. The bi-directional contagion between equity and the 1-year bond, coupled with the relatively frequent realisation of turbulent shocks to the latter and their high persistence make the shorter-horizon bond less attractive to an equity investor.

The second method of trying to identify the most suitable safe haven asset is to appeal more to the economic, rather than the statistical, significance of our results. In particular, we examine the asset variances and covariances by state and decompose the totals into the contributions coming from each of the shocks. Fig. 4 presents the conditional variance of each asset by state.

The most striking feature of Fig. 4 is that the conditional variance of gold - the potential safe haven asset - is larger than that of equity in a number of regimes. In fact, this is always the case when the gold idiosyncratic shock experiences high volatility. This is consistent with our summary statistics earlier where gold was identified as a highly volatile asset. In contrast, equity is always more risky than the Treasury bonds regardless of the state that we are in. Figs. 5 and 6 decompose the asset variances into the proportions due to the common shock, the asset's own idiosyncratic shock and a pure contagion (PC) effect arising from the spillover of a high-volatility shock to the other asset in the pair. 


\section{Equity \& Gold}

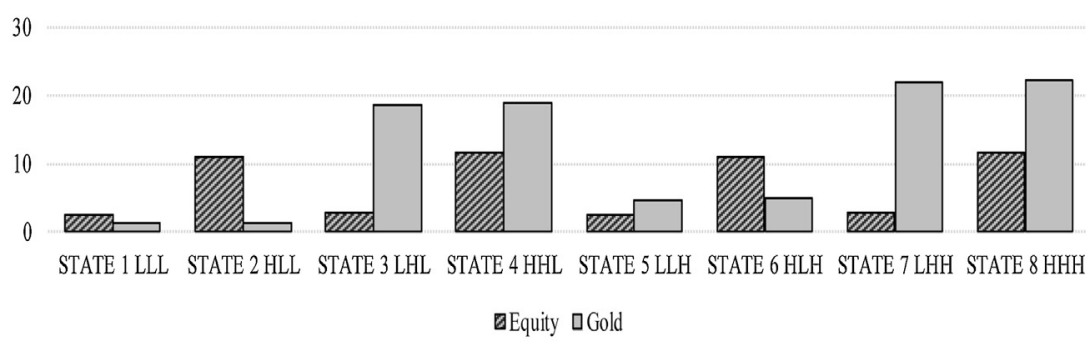

\section{Equity \& 10-Year Bond}

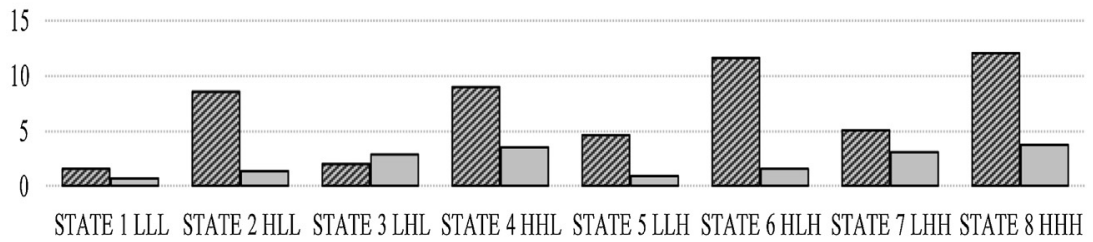

Equity $010-Y e a r B o n d$

\section{Equity \& 1-Year Bond}

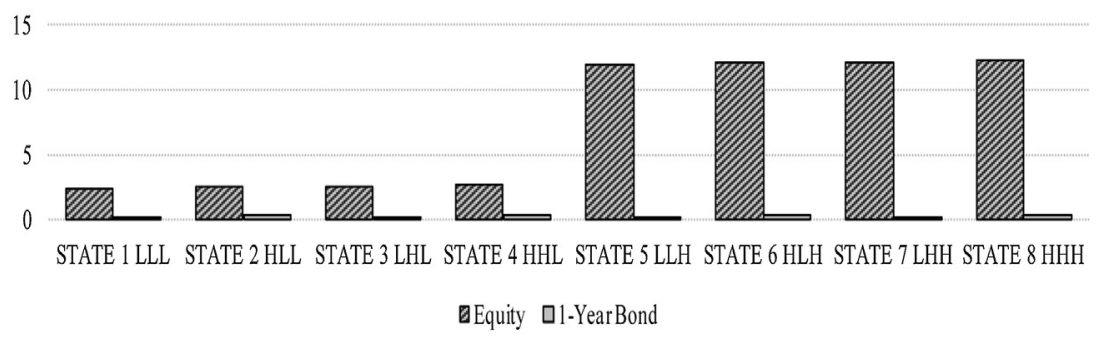

Fig. 4. Conditional variances by state. Notes: Let $i, j, k$ represent the equity, safe haven and common shocks respectively. Then State " $i, j, k$ " denotes each of the possible states where $i, j, k$ can equal either L (low volatility) or $\mathrm{H}$ (high volatility), so, for example, state 2 with $i=\mathrm{H}, j=k=\mathrm{L}$, captures the situation with the equity idiosyncratic shock is in the high-volatility regime, while the safe haven idiosyncratic shock and the common shock are both in the low-volatility regime.

Fig. 5 presents this decomposition for equity. The risk sources vary depending upon which asset equity has been paired with. Firstly, when combined with gold, the common shock has a negligible impact on the equity variance. Even in state 5 , where the common shock is the only asset experiencing high volatility, it only accounts for $1 \%$ of the variance. In fact, the own idiosyncratic shock dominates the variance and contributes at least $80 \%$ in all cases. When the gold idiosyncratic shock is in its highvolatility regime, it may generate pure contagious effects for the equity asset and we see its influence in states 3, 4, 7 and 8 . However, it never amounts to more than $20 \%$ and only then in the states where the equity shock is in its low-variance state.

In the equity - 10-year bond pair, the common shock is more influential but only when it is in the high-volatility regime. Again its own idiosyncratic shock accounts for the majority of the equity variance. There is some evidence of a spillover from a high-volatility shock to the longer-dated bond, particularly when it is the only asset experiencing large shocks (state 3 ). The 1 -year bond risk sources 


\section{(a) Gold}

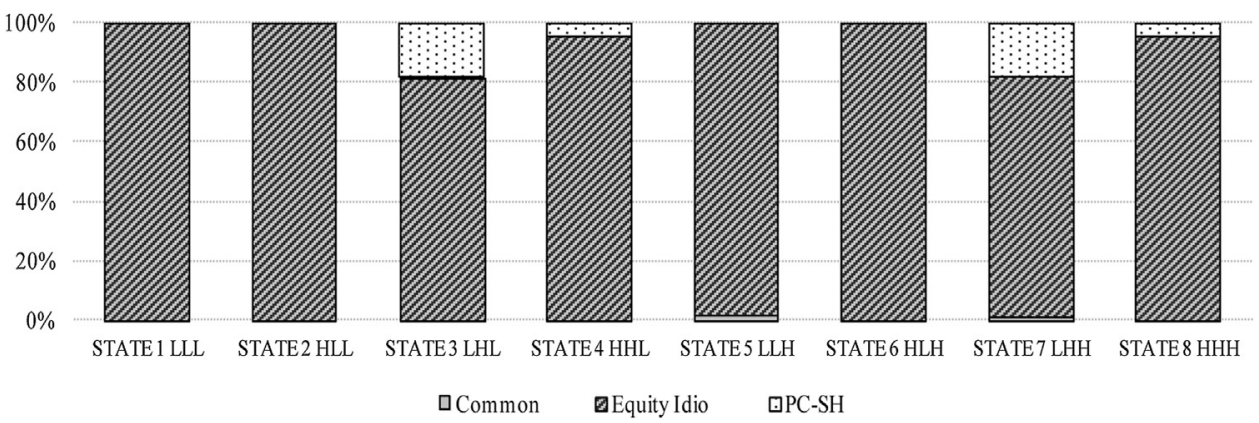

(b) 10-Year Bond

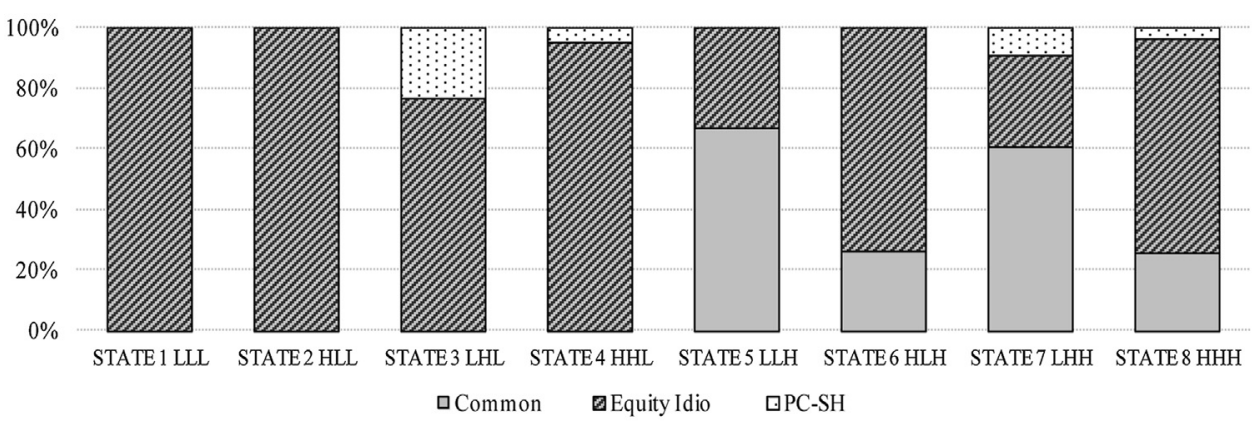

(c) 1-Year Bond

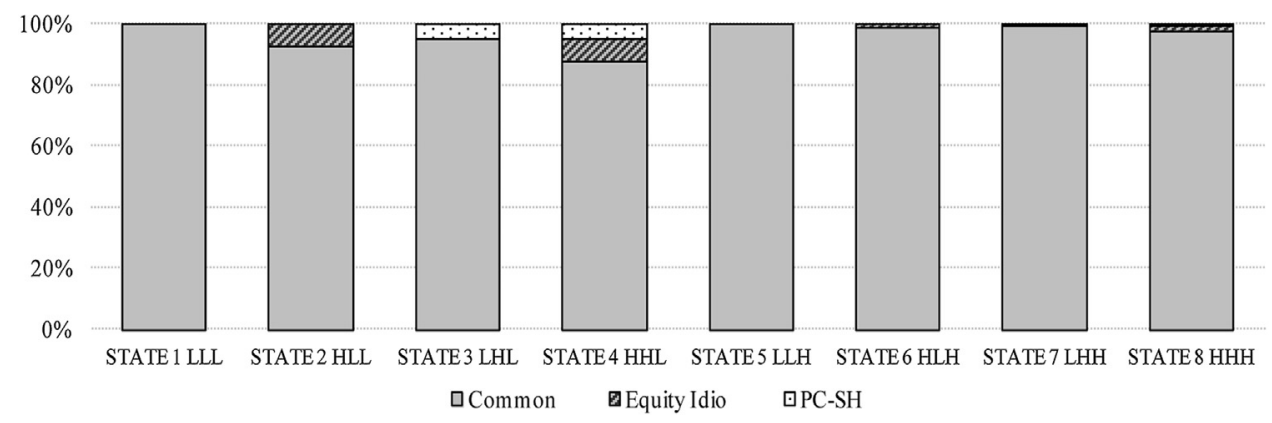

Fig. 5. Decomposition of equity variance by state in pairings with (a) gold, (b) 10 -year bond and (c) 1 -year bond. Notes: Let $i, j, k$ represent the equity, safe haven and common shocks respectively. Then State " $i, j, k$ " denotes each of the possible states where $i, j, k$ can equal either $\mathrm{L}$ (low volatility) or $\mathrm{H}$ (high volatility). 'Common' refers to the proportion of the total equity variance that can be attributed to the common shock, 'Equity Idio' represents the proportion arising from its own idiosyncratic shock, while 'PC-SH' captures the pure contagion (PC) effect that contributes to the total equity variance when the safe haven asset experiences a high-volatility idiosyncratic shock. This final component demonstrates the threat of contagion from holding a safe haven asset. Note that the contagion channel is only active when the safe haven idiosyncratic shock is in the high-volatility regime, i.e. $j=\mathrm{H}$, and so may potentially contribute to the equity variance in states $3,4,7$ and 8 . 


\section{Gold}

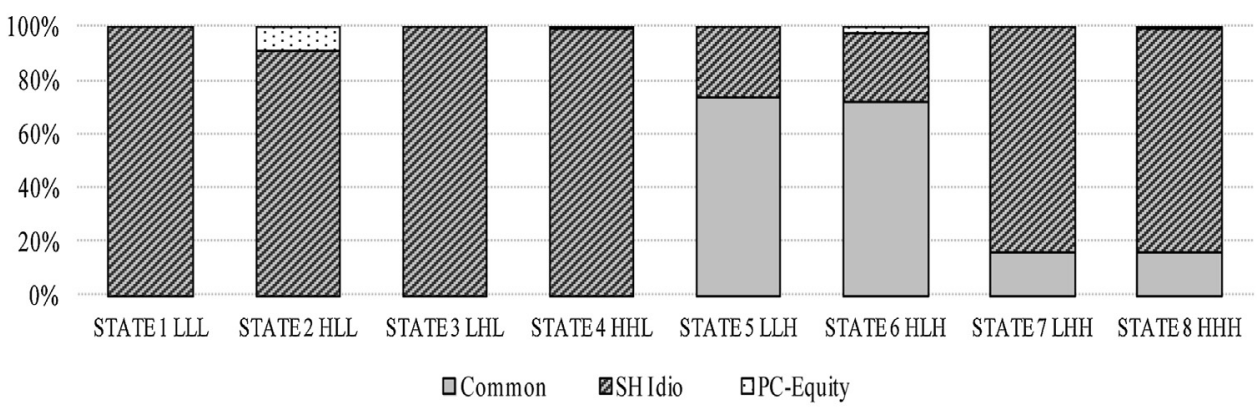

\section{0-Year Bond}

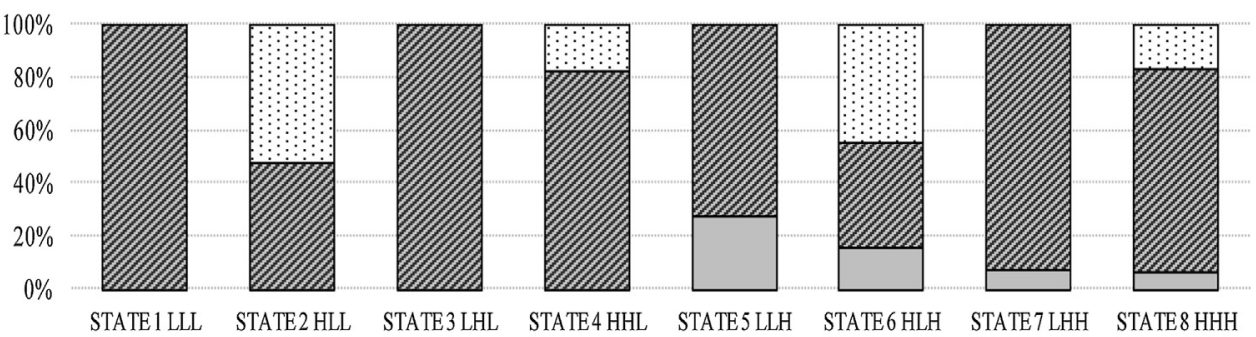

$$
\text { 口Common } \square \text { SHIdio } \square \text { PC-Equity }
$$

\section{1-Year Bond}

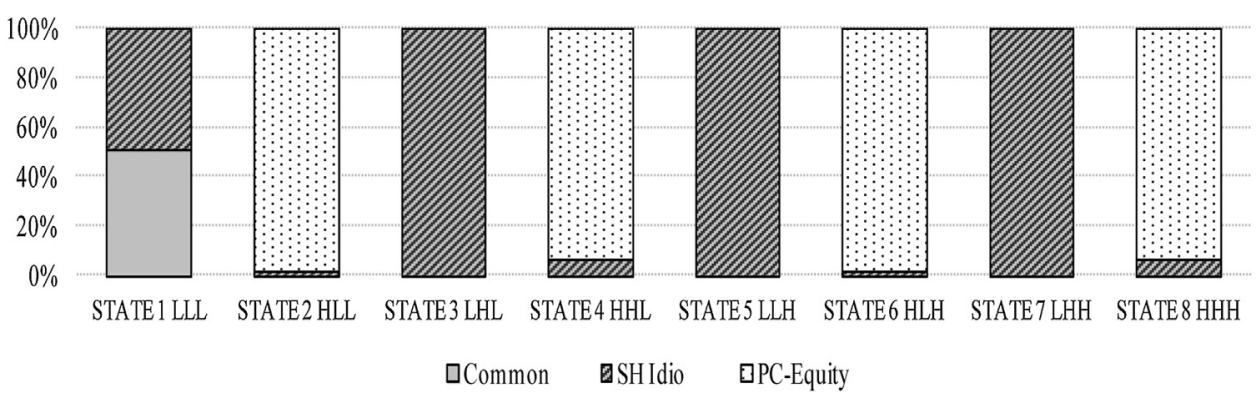

Fig. 6. Decomposition of variance of safe haven asset return by State. Notes: Let $i, j, k$ represent the equity, safe haven and common shocks respectively. Then State " $i, j, k$ " denotes each of the possible states where $i, j, k$ can equal either $\mathrm{L}$ (low volatility) or $\mathrm{H}$ (high volatility). 'Common' refers to the proportion of the total asset variance that can be attributed to the common shock, 'SH Idio' represents the proportion arising from its own idiosyncratic shock, while 'PC-Equity' captures the pure contagion (PC) effect that contributes to the total asset variance when equity experiences a high-volatility idiosyncratic shock. 'PC-Equity' captures the spillover from a high-volatility equity shock, which the investor is trying to diversify away. Note that the contagion channel is only active when the equity idiosyncratic shock is in the high-volatility regime, i.e. $i=\mathrm{H}$, and so may potentially contribute to the equity variance in states $2,4,6$ and 8 .

are very different, with the common shock dominating in every state. It swamps both idiosyncratic shocks and is by far the most important source of equity risk.

In summary, equity investors need not be overly fearful of the threat of pure contagion arising from high-volatility shocks to the safe haven asset. The economic significance of this channel is limited. 


\section{(a) Gold}

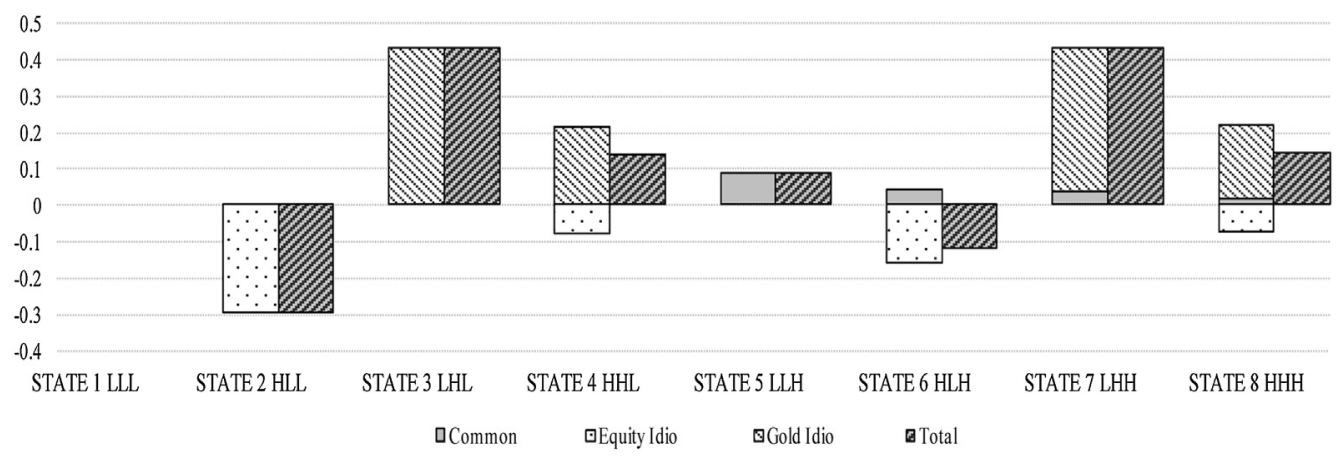

(b) 10-Year Bond

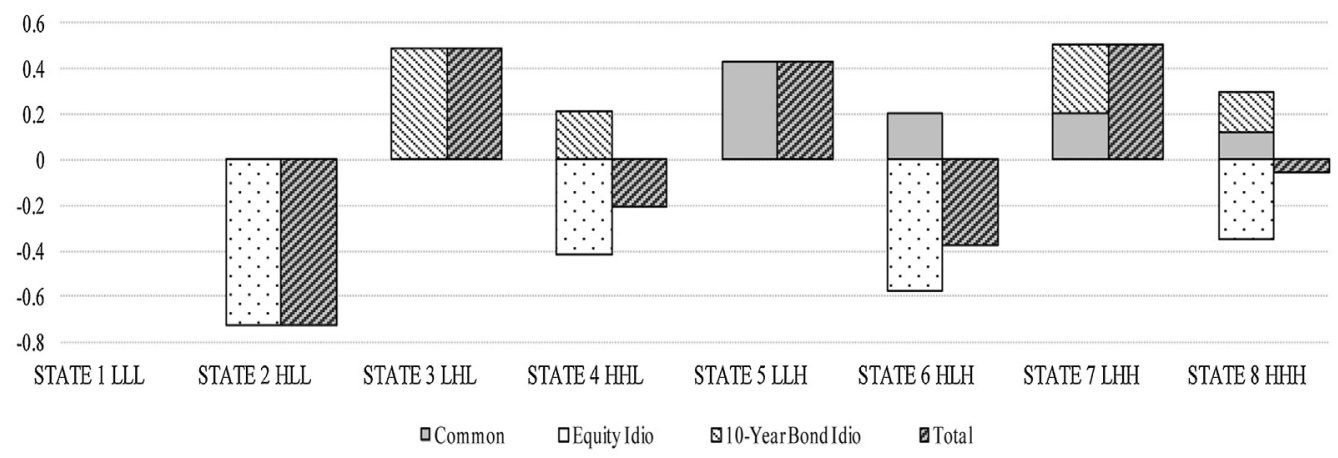

(c) 1-Year Bond

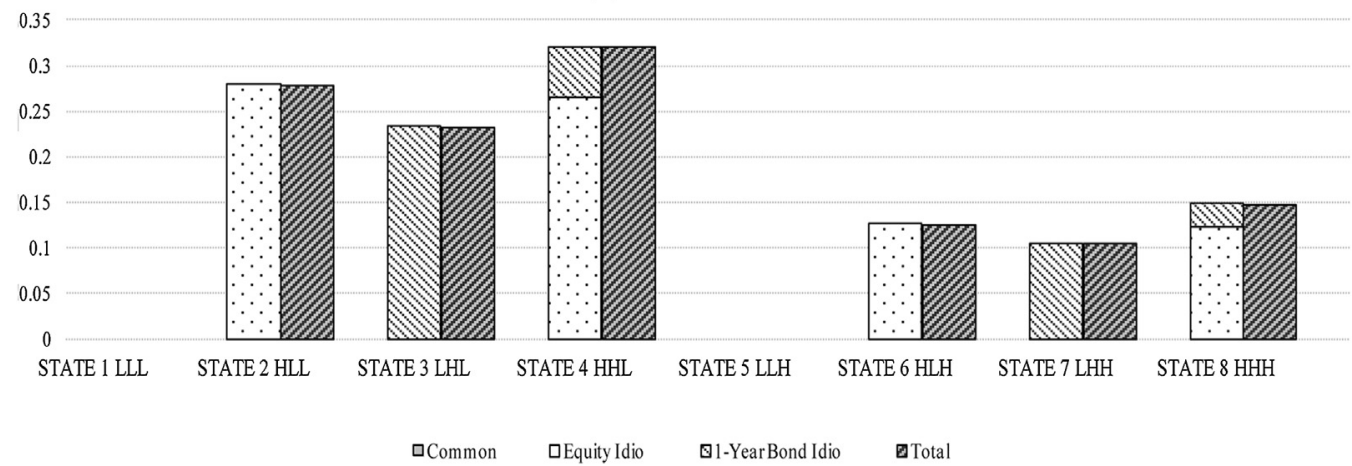

Fig. 7. Decomposition of equity correlation with (a) gold, (b) 10-year bond and (c) 1-year bond by shock and state. Notes: Let $i, j, k$ represent the equity, safe haven and common shocks respectively. Then State " $i, j, k$ " denotes each of the possible states where $\mathrm{i}, \mathrm{j}, \mathrm{k}$ can equal either $\mathrm{L}$ (low volatility) or $\mathrm{H}$ (high volatility). The total correlation is decomposed into the contribution of each shock; the common shock and the idiosyncratic shocks to equity and the safe haven asset. 
Fig. 6 presents the corresponding information for the candidate safe haven assets. Gold risk stems largely from its own idiosyncratic shock and the common shock when it transits to the turbulent regime. Contagion from the equity market matters little. Its only influence occurs in state 2 , when the equity idiosyncratic shock is the only shock experiencing high volatility. Pure contagion is a more worrying phenomenon for the Treasury bonds. In the states when the equity idiosyncratic shock experiences high volatility (states 2, 4,6 and 8), the contagious effect plays a significant role, especially for the shorter-dated bond. In these states, spillovers from equity shocks account for almost all of the 1 -year bond risk. Therefore equity investors may be reluctant to use the shorter-dated bond as a diversification vehicle as it is susceptible to contagious effects from the stock market. Common risk factors appear to be relatively unimportant.

Finally, and maybe most importantly for understanding the portfolio benefits of holding a safe haven asset, we look at the comovements between equity and each of the assets under consideration. Fig. 7 presents the total correlation by state, decomposed into the three risk channels. A desirable feature of a safe haven asset would be to reduce correlation when the equity asset experiences increased volatility.

Firstly, correlations during tranquil periods (state 1, where all shocks are in their low-volatility regimes) are close to zero so this serves as our benchmark. Whenever equity-specific shocks are in high volatility, the flight-to-quality effects documented for gold and the longer-horizon bond always reduce correlation. In fact, in the case of the 10-year bond, the total correlation is always negative in these states of the world, earmarking it as a suitable safe haven for equity investors. For gold, sometimes this negative effect can be offset by its own idiosyncratic shock to leave the total correlation mildly positive (e.g. states 4 and 8). For each state that involves a high-volatility equity idiosyncratic shock, the correlation between equity and the 10-year bond is smaller (more negative) than for any of the other potential safe haven assets. This analysis of correlation fails to provide any support for the 1-year Treasury bond as a safe haven asset. Its correlation with equity is always positive. Furthermore, the bi-directional contagion channels always work to increase the correlation during periods of asset turbulence. Only in state 5, when both idiosyncratic shocks are in a low-volatility regime and the common shock is in the turbulent state, is the correlation unaffected. This is consistent with our earlier finding that the 1-year Treasury bond is insensitive to the common shock and thus provides a good hedge against common risk sources.

In summary, both gold and the 10-year Treasury bond bear many of the characteristics that investors seek from a safe haven asset. The shorter-dated bond fails to provide such portfolio insurance. Held in isolation, gold is a low-return, high-risk asset but when combined with equity, it tends to produce stable portfolios. Its ability to offset negative equity-specific shocks and deliver better returns earmarks it as a safe asset during market turbulence. The 10-year bond is a low-risk alternative safe haven. It will always deliver more stability but is unlikely to increase returns as much as gold. The choice between gold and long-term bonds may ultimately depend on the fund manager's attitude to risk.

\section{Conclusions}

We assess a number of potential safe haven assets from the perspective of an equity investor. We analyse the claims of gold, a 10- and 1-year Treasury bond. We employ a flexible regime-switching model which allows us to separate common and idiosyncratic risk factors. We find that the 1-year bond is a good hedge against common risk sources but these play a relatively minor role. Asset returns are more sensitive to idiosyncratic risks and these are more influential in our choice of safe haven asset.

Idiosyncratic shocks may spillover to other assets during periods of market turbulence. The equity - 1-year bond combination suffers from bi-directional contagion, making it a highly risky portfolio. Shocks originating in either the gold or the longer-dated bond market may also cause contagion in equity markets but these shocks are relatively infrequent and not very persistent. They are more than offset by a 'flight-to-quality' effect that is found whenever there are high-volatility idiosyncratic shocks in equity markets. This effect tends to reduce correlation and enhance the return of the safe haven asset when the stock market experiences episodes of large fluctuations. 
Therefore, both gold and long-horizon Treasury bonds deliver many of the characteristics required from a safe haven asset. Both reduce correlation during periods of equity market turbulence and it's always negative for the equity - 10-year bond pair. Gold has a higher expected return during the highvolatility regime and its own variance is more insulated from contagious effects. Gold is the more risky asset so the choice between the two is likely to reflect the equity fund manager's tolerance of risk.

\section{References}

Andersson, M., Krylova, E., Vähämaa, S., 2008. Why does the correlation between stock and bond returns vary over time? Applied Financial Economics 18 (2), 139-151.

Baele, L., Bekaert, G., Inghelbrecht, K., 2010. The determinants of stock and bond return comovements. Review of Financial Studies 23 (6), 2374-2428.

Baur, D.G., Lucey, B.M., 2010. Is gold a hedge or a safe haven? An analysis of stocks, bonds and gold. Financial Review 45 (2), $217-229$

Baur, D.G., McDermott, T.K., 2010. Is gold a safe haven? International evidence. Journal of Banking \& Finance 34 (8), 1886-1898.

Cappiello, L., Engle, R.F., Sheppard, K., 2006. Asymmetric dynamics in the correlations of global equity and bond returns. Journal of Financial Econometrics 4, 537-572.

Chan, K.F., Treepongkaruna, S., Brooks, R., Gray, S., 2011. Asset market linkages: evidence from financial, commodity and real estate assets. Journal of Banking and Finance 35, 1415-1426.

Connolly, R., Stivers, C., Sun, L., 2005. Stock market uncertainty and the relation between stock and bond returns. Journal of Financial and Quantitative Analysis 40, 161-194.

Coudert, V., Raymond, H., 2011. Gold and financial assets: are there any safe havens in bear markets? Economics Bulletin 31 (2), 1613-1622.

De Goeij, P., Marquering, W., 2004. Modeling the conditional covariance between stock and bond returns. a multivariate GARCH approach. Journal of Financial Econometrics 2 (4), 531-564.

Flavin, T.J., Panopoulou, E., Unalmis, D., 2008. On the stability of domestic financial market linkages in the presence of timevarying volatility. Emerging Markets Review 9 (4), 280-301.

Fleming, J., Kirby, C., Ostdiek, B., 1998. Information and volatility linkages in the stock, bond, and money markets. Journal of Financial Economics 49 (1), 111-137.

Gravelle, T., Kichian, M., Morley, J., 2006. Detecting shift-contagion in currency and bond markets. Journal of International Economics 68 (2), 409-423.

Guidolin, M., Timmermann, A., 2006. An econometric model of nonlinear dynamics in the joint distribution of stock and bond returns. Journal of Applied Econometrics 21 (1), 1-22.

Hillier, D., Draper, P., Faff, R., 2006. Do precious metals shine? An investment perspective. Financial Analysis Journal 62 (2), 98-106.

Jaffe, J.K., 1989. Gold and gold stocks as investments for institutional portfolios. Financial Analysts Journal 45 (2), 53-59.

Kaul, A., Sapp, S., 2006. Y2K fear and safe haven trading of the US dollar. Journal of International Money and Finance 25, $760-797$.

Kim, S.-J., Moshirian, F., Wu, E., 2006. Evolution of international stock and bond market integration: influence of the European Monetary Union. Journal of Banking and Finance 30, 1507-1534.

Lawrence, C., 2003. Why is Gold Different from other Assets? An Empirical Investigation. The World Gold Council, London, UK.

McCauley, R.N., McGuire, D., 2009. Dollar appreciation on 2008: safe haven, carry trades, dollar storage and over hedging. Bank for International Settlements Quarterly Review. International Banking and Financial Market Developments 2009, 85-93.

Morningstar, 2008. Return Calculation of U.S. Treasury Constant Maturity Indices. Methodology Paper.

Schwert, G.W., 1989. Why does stock market volatility change over time? Journal of Finance 44 (5), $1115-1153$.

Scruggs, J.T., Glabadanidis, P., 2003. Risk premia and the dynamic covariance between stock and bond returns. Journal of Financial and Quantitative Analysis 38 (2), 295-316.

Steeley, J.M., 2006. Volatility transmission between stock and bond markets. Journal of International Financial Markets, Institutions and Money 16, 71-86. 